\title{
Apropiaciones espaciales de la danza: del espacio privado al espacio público
}

\author{
MARTA LLORENTE PASCUAL \\ Arquitecto. Doctoranda en la Escuela Técnica Superior de Arquitectura \\ Universidad Politécnica de Madrid \\ llomar2012@gmail.com
}

\begin{abstract}
Resumen
La arquitectura como arte mediador entre el mundo y el hombre siempre ha jugado un importante papel, iniciando, organizando y dirigiendo el movimiento, como si de un coreógrafo se tratase. Este artículo estudia la relación inseparable de la danza y la coreografía con la arquitectura y el espacio, sin embargo desde otro punto de vista: analizando el recorrido de las apropiaciones espaciales de la danza, su interacción con la arquitectura y la ciudad. Este diálogo entre disciplinas, tiene su origen en la antigüedad, su efervescencia a principios del siglo XX con las Vanguardias y la Performance mediante la descontextualición de las distintas formas de arte y llega hasta nuestros días a través de coreógrafos como Trisha Brown, Pina Bausch, Sasha Waltz, Anne Teresa de Keersmaeker, Wim Vandekeybus así como numerosas iniciativas que entrelazan la danza y el espacio urbano. Se pone en relieve el análisis de la obra de Anne Teresa de Keersmaeker como ejemplo clave.
\end{abstract}

Palabras clave: Arquitectura; espacio público; ciudad; danza; coreografía; diálogo; apropiaciones espaciales.

$$
\begin{gathered}
\text { Space appropriations of dance: } \\
\text { from private space to public space }
\end{gathered}
$$

\begin{abstract}
Architecture has always played a very important role as a mediating art between man and the world: initiating, organising and directing movement, as if it were a choreographer. This article studies the inseparable relationship that dance and choreography have to architecture and space, albeit from a different point of view:
\end{abstract}


analysing the path of dance's spatial appropriations, it's interaction with architecture and with the city. This dialogue between disciplines has its origins in the ancient world, and reaches a boom period at the beginning of the 20th century with the Vanguards (New Dance pioneers) and later on with Performance Art, through the decontextualization of different art forms. It arrives to present times through choreographers such as Trisha Brown, Pina Bausch, Sasha Waltz, Anne Teresa de Keersmaeker and Wim Vandekeybus as well as through many initiatives all over the world that weave together dance and urban space. A study of the work of Anne Teresa de Keersmaeker will be focused on as a key example.

Key words: Architecture, public space, city, dance, choreography, dialogue, communication, spatial appropriations.

Sumario: 1.- Introducción. Relación danza-espacio. 2.- Tránsito del espacio privado al espacio público en la danza. Breve recorrido histórico. 3.- Interacción espacial en la obra de Anne Teresa de Keersmaeker. 4.- Violin Phase 1981-2011. 5.- Ma mère l'oye 2001. 6.Counter Phrases 2003. 7.- Ball moderne Lisboa 2012. 8.- Referencias bibliográficas.

\section{Introducción. Relación danza-espacio.}

Desde allí al cabo de seis días y seis noches, el hombre llega a Zobeida, ciudad blanca, bien expuesta a la luna, con calles que giran sobre sí mismas como un ovillo. De su fundación se cuenta esto: hombres de naciones diversas tuvieron el mismo sueño, vieron una mujer que corría de noche por una ciudad desconocida, la vieron de espaldas, con el pelo largo, y estaba desnuda. Soñaron que la seguían. Al final tras muchas vueltas todos la perdieron. Después del sueño buscaron aquella ciudad; no la encontraron pero se encontraron entre sí decidieron construir una ciudad como en el sueño. En la disposición de las calles cada uno repitió el recorrido de su persecución; en el punto donde había perdido las huellas de la fugitiva, cada uno ordenó los espacios y los muros de manera distinta que en el sueño, de modo que no pudiera escaparse más (Calvino, 2000:59).

Las estrechas conexiones de la Arquitectura y la ciudad con otras Artes se presentan desde la antigüedad, de Fidias a Brunelleschi y Miguel Ángel, idas y venidas de la escultura o la pintura a la arquitectura; sin embargo lo que me ocupa en esta comunicación es la relación de otro arte, la Danza, con los 
espacios y las arquitecturas que la albergan y ella ocupa. A pesar de que la Arquitectura y las trazas de la ciudad actúan como coreógrafos que van dictando el movimiento a los habitantes, en otra capa aparece la danza apropiándose de estos lugares y dialogando con ellos. La Danza entendida como modo de expresión para habitar espacios, empezando por el del cuerpo, toma posesión de ellos, teje sus redes invisibles y así ambos cobran sentido. Como el anterior fragmento que nos describe el origen de una ciudad y que presenta muchas similitudes con el mito de Teseo y su baile del laberinto o Geranos.

Fig. 1.

Teseo y Ariadna al lado del laberinto de Creta. Fuente: 1460-1470 baccio+baldini+teseo+and+ ariadna+la+lado+de+creta+1460-1470.JPG y littlethingsandbigthings.blogspot.com

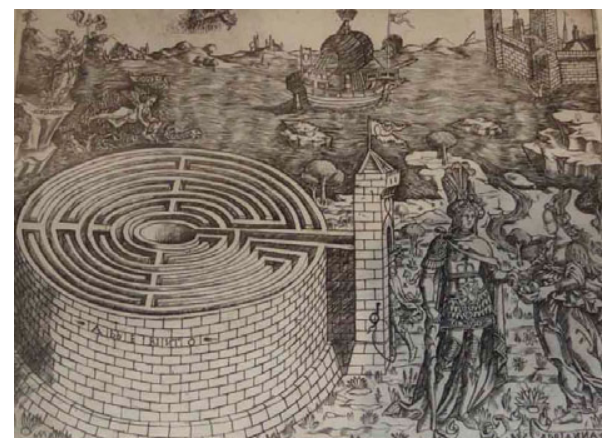

En la experiencia del arte tiene lugar un peculiar intercambio; yo le presto mis emociones y asociaciones al espacio y el espacio me presta su aura, que atrae y emancipa mis percepciones e ideas. Una obra de arquitectura no se experimenta como una serie de imagines retinianas aisladas, sino en su esencia material, corpórea y espiritual plenamente integrada.

Los edificios y las ciudades proporcionan el horizonte para entender y confrontar la condición humana existencial. En lugar de crear simples objetos de seducción visual, la arquitectura relaciona media y proyecta significados. (Pallasma, 2010:

Por Otra parte el estudio del cuerpo en el espacio ha sido un tema que ha preocupado a la arquitectura a lo largo de la historia, aunque en la mayoría de las ocasiones bajo un prisma meramente antropomórfico y antropométrico. Así mismo es en el S.XX cuando aparece un desarrollo sin precedentes en materia corpóreo-espacial de la mano de las nuevas prácticas espaciales (Danza contemporánea y performance) y se incorporan nuevas apreciaciones.

Ha llegado el momento de tomar conciencia del espacio como fluido. No se trata 
sólo de un espacio visto por los ojos, sino de un espacio recorrido por el cuerpo. El primer elemento espacial del que hemos sido conscientes ha sido el tiempo, su medida en el espacio, la distancia, la línea recta. Pero hoy en día tenemos que concebir la curvatura del espacio. Su medida forma parte de la multidireccionalidad del espacio (Laban, 2003).
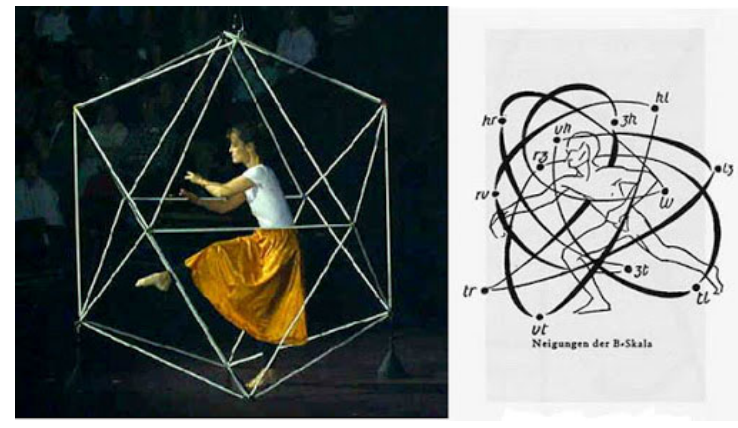

Fig. 2. Icosaedro de R. Laban. Trazos de movimiento. Fuente: Laban_icosaedro_\%5B1\%5D.jpg spacioars.blogspot.com

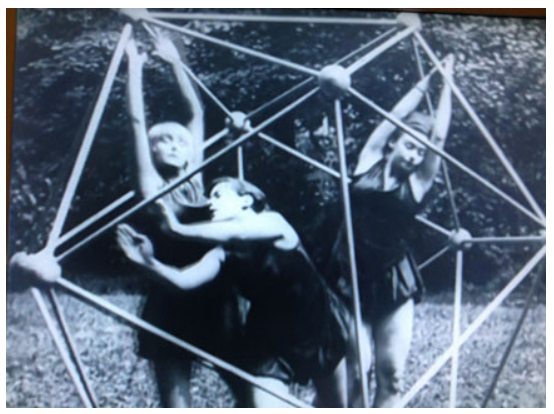

Fig. 3. Icosaedro de R. Laban. Fuente: Exposición "Danser sa vie" C. G. Pompidou, Paris, 2012.

Esta unión inseparable del cuerpo y el espacio a través del tiempo, las resonancias que el uno provoca en el otro crean una fuerte simbiosis que hace que uno no pueda entenderse sin el otro.

Yo enfrento la ciudad con mi cuerpo; mis piernas miden la longitud de los soportales y la anchura de la plaza; mi mirada proyecta inconscientemente mi cuerpo sobre la fachada de la catedral, donde deambula por las molduras y los contornos, sintiendo el tamaño de los entrantes y salientes; el peso de mi cuerpo se encuentra con la masa de la puerta de la catedral y mi mano agarra el tirador de la puerta al entrar en el oscuro vacío que hay detrás. Me siento a mí mismo en la ciudad y la ciudad existe a través de mi experiencia encarnada. La ciudad y mi cuerpo se complementan y se definen el uno al otro. Habito en la ciudad y la ciudad habita en mí. (Pallasma, 2010:41:42).

\section{Tránsito del espacio privado al espacio público en la danza. Breve recorrido histórico.}

A continuación paso a analizar los vínculos que naturalmente se han creado entre estas dos disciplinas, más profundamente de forma 
unidireccional de la danza hacia la arquitectura y la ciudad. Mediante un recorrido histórico analítico de la idea de espacio en la danza y de su transición desde un espacio más "privado" o cerrado a un contexto más público y urbano. Llegando a ser los espacios públicos una herramienta fundamental y muy enriquecedora de las coreografías actuales.

La danza ha formado parte de la Historia de la Humanidad desde el principio de los tiempos. Las pinturas rupestres encontradas en España y Francia, con una antigüedad de más de 10.000 años, muestran dibujos de figuras danzantes asociadas con ilustraciones rituales y escenas de caza. Esto nos da una idea de la importancia de la danza en la primitiva sociedad humana, sin embargo en estos primeros momentos no se presta mayor atención a la componente espacial.

En el antiguo Egipto, donde las danzas ceremoniales fueron instituidas por los faraones; culminaban en ceremonias representando la muerte y la reencarnación del dios Osiris se fueron haciendo cada vez más complejas hasta el punto de que sólo podían ser ejecutadas por profesionales altamente cualificados Grecia aparecen como medio de comunicación con los dioses, como Arte en toda regla, con una musa dedicada a ella: Terpsícope. Los primeros vestigios provienen de los cultos a Dionisio, mientras que fue en las tragedias donde, se desarrolla como técnica, en los movimientos rítmicos del coro. Como parte de la mitología se cree que proviene del mito del Laberinto de Teseo, con las danzas Geranos. El mayor apogeo tiene lugar en la época clásica con más de 200 danzas (religiosas, atléticas, dramáticas y populares) que se desarrollan en espacios arquitectónicos claves de la polis griega: el teatro, el estadio y el templo. La idea espacial de la danza griega, destaca el volumen, es muy aérea en sus movimientos y ligada a la forma. Esta danza que ejercerá gran influencia posteriormente en coreógrafos del S. XX como Isodora Duncan.

Aunque mi danza debe su inspiración a los griegos, no es realmente griega, sino muy moderna: es mi propia idea.

En ningún otro país es el alma tan sensible a la Belleza y a la Sabiduría como en Grecia. Mirando al cielo se sabe por qué Atena, la Diosa de la Sabiduría, fue llamada "ojizarca", y por qué el aprendizaje y la belleza se unen siempre a su servicio.

Y se siente también porque Grecia ha sido la tierra de los filósofos, amantes de la sabiduría, y por qué los más grandes entre éstos han identificado la máxima 
belleza con la sabiduría... (Duncan, 2008: 68).

En Roma se difumina, se desdibuja y pierde mucha importancia y con ello el concepto espacial de la misma pierde igualmente importancia. Durante la Edad Media, queda reprimida fruto de la moral y cultura del momento, quedando relegada a danzas populares, danzas bajas, danzas de la muerte. El concepto espacial pasa a un segundo plano, sin embargo posteriormente en el siglo XX los expresionistas alemanes retomaran imágenes medievales (" $\mathrm{La}$ mesa verde" Kurt Joos) fusionándolas con los conceptos espaciales por ellos desarrollados (linealidad, geometría...).

El Renacimiento proporciona un respiro y trae una nueva actitud hacia el cuerpo, las artes y la danza. Las cortes de Italia y Francia se convirtieron en el centro de nuevos desarrollos en la danza gracias a los mecenazgos a los maestros de la danza y a los músicos que crearon grandes danzas a escala social que permitieron la proliferación de las celebraciones y festividades. Al mismo tiempo la danza se convirtió en objeto de estudios serios y un grupo de intelectuales autodenominados la Pléyade trabajaron para recuperar el teatro de los antiguos griegos, combinando la música, el sonido y la danza.

En 1451 aparece uno de los primeros tratados sobre el arte coreográfico De arte saltandi et choreas ducendi de Doménico da Piacenza, figura de gran importancia puesto que con él la coreografía se convierte en un oficio profesional. Da Piacenza deseaba elevar la danza de arte mecánica a arte liberal como la música. La teoría del tratado pretende demostrar que la danza es una virtud y, como tal, debe ser considerada al mismo nivel de la música. En él distingue cinco elementos en la danza: Compás de medida, la musicalidad, la manera, la memoria, la división del terreno, el aire, y dos tipos de pasos (pasos naturales, andar y accidentales, entrechat, paso corrido y cambio depie) supone un cambio de actitud ante el conocimiento y la percepción del mundo: el Humanismo. Aparece la danza como consecuencia de la nueva organización social, con la burguesía Posteriormente se escriben otros manuales teóricos sobre la práctica de la danza, así en 1588 aparece Orchesographie de Thoinot Arbeau, que constituyó la principal fuente de información sobre la danza renacentista. Tienen lugar colaboraciones con otros artistas y disciplinas, aparecen las escenografías: Leonardo da Vinci, Botticelli, Alberti, Brunelleschi, Mantegna, y Poliziano pintaron y diseñaron 
escenografías para representaciones teatrales.

En el siglo XVI aparece en Francia el Ballet Comique (Catalina de Medici y Enrique de Orleans, que lo utilizan como arma diplomática), será el germen del ballet como lo conocemos actualmente. En el Ballet comique de la reine Luoise de 1581, considerado como el punto de partida de la historia del ballet, se da una simbiosis del gusto italiano y francés en organización estética y coreográfica. Con el Rey Sol la danza se enraíza fuertemente, y será él, Louis XIV, quién dé mucha importancia al diseño espacial (incluso más que a la coreografía) a medida que se va desarrollando el "ballet de cour" va cobrando más importancia el espacio. Así mismo aparece y se desarrolla en gran medida la coreografía del "recorrido" (Parcours) y serán los jardines, sobre todos los de Versalles, los que configuren las escenografías de muchas danzas. Se da un gran paso adelante en el acercamiento de la danza a espacios más abiertos, exteriores, ideas de recorridos, inclusión de la naturaleza como telón de fondo, emancipación de espacios recogidos, contenedores, más privados, que habían sido predominantes hasta entonces. Veremos que posteriormente en la historia se retoman estas tendencias y coreógrafos actuales desarrollan muchas de sus piezas en este tipo de espacios (Anne Teresa de Keersmaeker, que veremos posteriormente, Wim Van de Keybus el. Siglo XVII va a ser Inglaterra la protagonista, declina el "Ballet de cour" y aparecen las Masques Court Revels (Corte de Enrique VII), donde se conjuga la música, la poesía, la vestimenta y la danza, inspirándose en dramas italianos. Con Enrique VIII e Isabel I surge el "anti masque", gestos y elementos puramente coreográficos, la danza se establece con autonomía. En 1931 Ninette de Valois realiza "A masque for dancing" inspirándose en ello.

En 1661 acontece la profesionalización de la danza con la creación de la Real Academia de la Danza en Francia. Luis XIV la incluye en la Academia de la Música, como necesidad de llegar a más altos niveles de ejecución. Se codifica la danza Beauchamps, tradición de la "danse d'école". La danza asciende a los escenarios, aparecen nuevas exigencias coreográficas por las restricciones espaciales y visuales. Primacía de diseños geométricos en las coreografías y se introducen conceptos nuevos: a) "En dehors" a fin de permitir al público un ángulo de visión más amplio y desde distintos puntos de vista. b) Zapatos cortesanos. c) Independencia del torso con respecto al resto de cuerpo. d) Se codifican las cinco posiciones de los pies con sus 
respectivas en los brazos, "port de bras" (distintos ángulos de apertura de los pies y posición correlativa de los brazos con respecto al eje del cuerpo).

Será también durante el reinado de Luis XIV de Francia, cuando por primera vez se empezó a separar el ballet profesional de la danza de la corte, apareció un sistema de notación completamente desarrollado. En 1700 el maestro de danza francés Raoul Auger Feuillet publicó su Choréographie, ou l'art d'écrire la danse. Podemos apreciar en estos primeros dibujos que tanto la relación del bailarín con respecto a su entorno, como el esquema en el suelo están representados en una línea a lo largo de la cual se escriben los pasos y algunos movimientos de brazos. Tras la creación de la Real Academia de la Danza en 1661, sólo unas décadas más tarde en aparecer la Escuela de Ballet de la Ópera de Paris en 1713, así la "danse de d'école" queda establecida y codificada para su desarrollo posterior.

La danza continuará su desarrollo a lo largo del siglo posterior, dejando ya perfectamente establecidas las bases que permiten explicar la aparición y el triunfo en el siglo XIX del ballet como arte escénico. Sin embargo desde el punto de vista espacial durante el siglo XIX tiene lugar un estancamiento, y la danza se concibe de una manera bidimensional, bastante frontal, con la primacía de la verticalidad, la ingravidez y la forma. Igualmente los espacios vuelven a recogerse y predomina "la caja mágica" frente a cualquier otra propuesta. Así el ballet romántico refleja el culto de la bailarina y la lucha entre el mundo terrenal y el mundo espiritual que trasciende la tierra, ejemplarizado en obras tales como Giselle (1841), Swan Lake (1895), y Cascanueces (1892).

Será a finales del siglo XIX cuando las artes en general hacen un serio cuestionamiento de valores y buscan nuevas formas de reflejar la expresión individual y un camino de la vida más dinámico. En Rusia surge un renacimiento del ballet propiciado por los más brillantes coreógrafos, compositores, artistas visuales y diseñadores. Serán los Ballets Rusos de Diágilev (19071929). En esta empresa colaboraron gentes como: Ana Pavlov, Claude Debussy, Stravinsky, Pablo Picasso... Surge la figura del coreógrafo como autor, superponiéndose al anterior protagonismo de la "Prima Bailarina". Y se concibe el Ballet como Obra de Arte total, como crisol dialógico del mopnentalamente a la revolución del Ballet surgieron las vanguardias y la Bauhaus y de su mano las primeras manifestaciones de las danzas modernas. 
Como reacción a los estilizados movimientos del ballet y la progresiva emancipación de la mujer surgió una nueva forma de bailar que potenciaba la libre expresión. Si por algo se ha caracterizado la danza contemporánea, respecto a su antecesora, la danza clásica, ha sido por un nuevo entendimiento del cuerpo y del espacio, así como por el nacimiento de una nueva relación entre ambos.

A comienzos del siglo XX las pioneras, Duncan y Fuller, se liberaron de sus zapatillas de punta y de la técnica clásica apostando por un movimiento libre y natural del cuerpo. Rudolf von Laban (años 20-30), Martha Graham, Mary Wigman, Kurt Joos (años 30) reclaman un nuevo cuerpo "pesado" a través de su trabajo con la gravedad. Espacialmente se vuelve a conceptos antiguos como los griegos o los renacentistas, y la danza comienza a abandonar los espacios cerrados y convencionales. Se acentúa la descontextualización espacial tanto de la danza como de todas las artes.

A este respecto Mary Wigman comenta en 1968 refiriéndose a la danza de expresión: La conciencia nuevamente adquirida del espacio y del ritmo se destaca en todo el teatro de hoy en día. Tanto en la ópera como en el teatro dramático, la danza moderna ha dejado sus huellas en el resto de la artes (Colomé, 1989:83).

En los años 50-60 Merce Cunningham, que se había formado con Martha Graham, recupera el empleo de la danza clásica como medio de conocimiento corporal y será un exponente máximo del paisaje dialógico (colaborando constantemente con músicos y artistas intercambiando conocimiento), desarrollando una técnica propia en la que introduce conceptos como la desjerarquización del espacio, el caos y la aleatoriedad. Utilizando espacios no convencionales para sus performances Merce Cunningham da comienzo a toda una era en la que las apropiaciones espaciales de la danza van a ser cada vez más ricas y sorprendentes; el espacio cerrado, estático, la caja escénica se verá sustituida por multitud de espacios que comenzando en museos, galerías de arte, llegan a parques y espacios urbanos. Estos primeros pasos dados por Merce Cunningham van a ejercer gran influencia en muchos de los coreógrafos posteriores. ér línea de investigación aparece la figura de William Forsythe, norteamericano que después de una formación clásica y moderna viene a Europa (años 70), de la mano de Kranko y representará una figura clave dentro de la investigación dialógica de la danza y el espacio. 
En 1962 se funda la Judson Dance Theater en NY, como centro de danza y arte experimental. Artistas como Yvonne Rainer, Steve Patxon, Trisha Brown, Lucinda Childs o Simone Forti sintieron la necesidad de salir a conquistar el espacio urbano ampliando así el registro espacial de la danza y la coreografía. Todos ellos, entre muchos otros son ejemplos de una nueva concepción espacio-corporal, que se enfrenta a la tradición clásica la cual había considerado el espacio como una malla geométrica sencilla y el cuerpo como un instrumento que, con trabajo debe aparentar ligereza y volatilidad.

Especial interés en el marco que nos ocupa presentan las primeras obras de Trisha Brown: Walking on the Wall (1971), Roof Piece (1973), Group primary accumulation (1973) y tantas otras, creadas para espacios no convencionales y concretamente urbanos. En Walking on the Wall bailarines con arneses caminan por la fachada de un rascacielos, mientras que Roof Piece ocurre en 12 cubiertas de edificios diferentes en un área de diez manzanas en la ciudad de Nueva York; los bailarines transmiten el movimiento al bailarín de la cubierta más cercana. Se podría decir que esta es la primera ocasión en la que la danza literalmente se apropia e interactúa con el espacio urbano. Este tipo de actuaciones va ejercer una gran influencia en posteriores coreógrafos, muchos proyectos actuales encuentran la inspiración directa en estas coreografías.

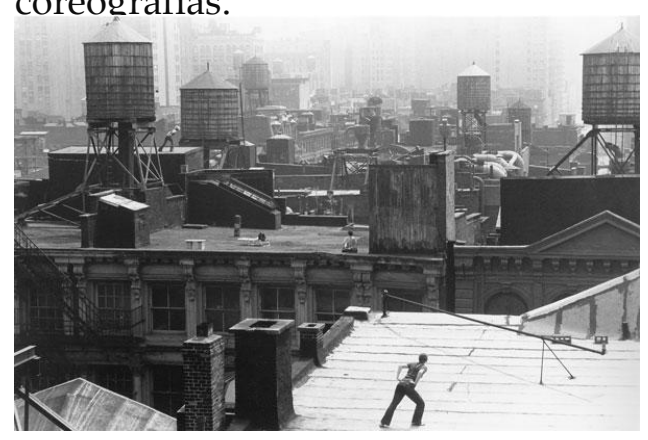

Fig. 4. Trisha Brown, Roof Piece originally performenced, 1971, NY.

Fuente: culturereport.wordpress.com

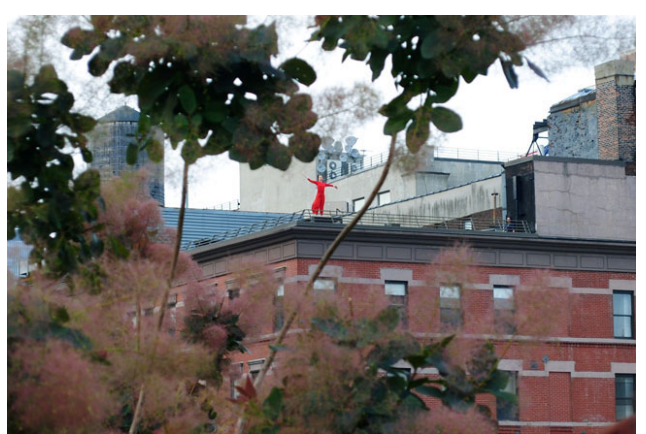

Fig. 5. Trisha Brown, 2011, NY. A dancer performing Trisha Brown's Roof Piece. Fuente: culturereport.wordpress.com

Durante las décadas de los 80 y 90 , el postmodernismo amplía el concepto iniciado por la danza moderna sigue llevándolo a cabo , sobre todo de la mano de compañías de danza contemporánea europeas; será la maduración de artistas cuya formación se basa en un amplio conocimiento de la vanguardia de las 
décadas 60 y 70.Cabe destacar Bélgica como país que produjo una Nueva Ola que incluía Jan Fabre, Anne Teresa de Keersmaeker, Jan Lauwers, Alain Platel y Wim Vankeybus. Estos artistas se encuentran en la posición única de crear material nuevo a partir de toda la herencia que han asimilado y al mismo tiempo apoyan a coreógrafos estadounidenses jóvenes como Meg Stuart y Mark Morris. En Alemania también existen figuras dignas de destacar como Pina Bausch, Susane Linke o Sasha Waltz. Prácticamente en las creaciones de todos los coreógrafos anteriores la búsqueda de la experimentación con nuevos espacios, no convencionales, la interacción con espacios urbanos es un denominador común.

Una mención especial a Pina Bausch, además de todo lo novedoso que su obra supone, de la acuñación de un género "danza Teatro" (ya esbozado por Kurt Joos y Mary Wigman de los que es legítima heredera) en cuanto a sus apropiaciones espaciales de contextos urbanos, la película realizada como obra póstuma por Wim Wenders en 2011 supone un exponente máximo del diálogo de la danza con la ciudad y la arquitectura (www.wim-wenders.com/movies/ movies_spec/pina/pina.htm).

Para concluir con este recorrido me parece fundamental apuntar los numerosos brotes de interacción de la danza con la arquitectura y la ciudad que surgen a finales del S.XX de manera totalmente explícita y continúa. No únicamente a través del "Site specific", creación de una pieza para un lugar concreto, investigando su "genius loci", como motor para el proyecto coreográfico (lo cual está siendo estos años una constante cada vez más habitual) sino como iniciativas que pretenden tejer redes internacionales de festivales de danza en paisajes urbanos.

Un ejemplo destacado y de origen español es la red Ciudades que danzan (CQD) que fue creada por la Associació Marató de l'espectacle en 1997 en Barcelona. Su objetivo es humanizar las ciudades, revalorizar su patrimonio artístico y arquitectónico, potenciar la danza en todos sus aspectos y fomentar el intercambio entre ciudades, creando un compromiso común de difusión artística. Actualmente realizan 28 festivales por más de 40 ciudades del mundo.

En el entorno madrileño aparece otra iniciativa en 2008 Invasión danza, que pretende la promoción de la danza, reclamando un papel activo y visible en la sociedad. Propone la experiencia de hacerse con espacios públicos para 
sorprender a nuevos "públicos", acercarles la danza; al mismo tiempo que investiga contextos inusuales, aprovechando las particularidades urbanísticas y arquitectónicas, tratando las posibilidades de interacción con la ciudadanía, sin previa convocatoria prueban el poder visual y estético que la danza puede tener en un contexto urbano, sin tener carácter de festival en absoluto, hasta ahora el número total de invasiones ha sido 133.

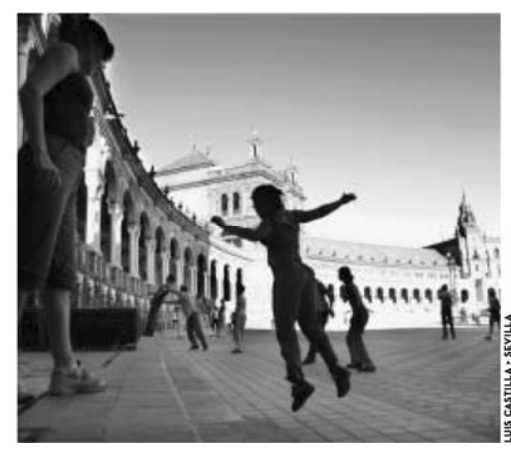

Fig. 6. Ciudades que danzan, Luis Castilla, Sevilla.

Fuente: www.cqd.info/index.php/es
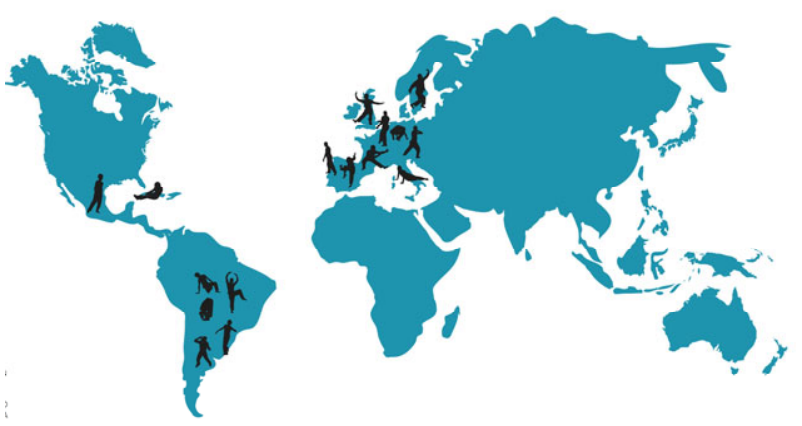

Fig. 7. Ciudades que danzan Fuente: www.cqd.info

Este tipo de iniciativas se dan a nivel internacional y son numerosas, por nombrar otro ejemplo en París surge el Paris Quartier d'été en 1990 a imagen de la ciudad como cruces de caminos, de rotondas de perspectivas, de avenidas, de edificios emblemáticos pero también de una periferia que existe paralelamente, buscando el mestizaje y el cruce de culturas (www.quartierdete.com /programme/spectacles/?id=866). En Dinamarca la coreógrafa Pipaluk, desarrolla el proyecto 100 dancers en 2011, otra idea de interacción interdisciplinar y dancística en el entorno urbano juntando a 100 bailarines y artistas de todo el mundo y que pretende el intercambio artístico dentro del campo de la danza y la creación de espectáculos de danza en espacios urbanos, tomando como tema central el "site specific" (www.liveartinstallations.com/100dancers).

\section{Interacción espacial en la obra de Anne Teresa de Keersmaeker.}

En el siguiente capítulo me centraré en el estudio de unas obras concretas de Anne Teresa de Keersmaeker como ejemplos de apropiaciones espaciales "urbanas" de la danza, entendidos como reformulaciones de antiguos 
parámetros pero vinculándolos con el presente. Igualmente plasmando el paralelismo de la evolución del concepto espacial en su obra, que parte de un punto muy intimista con espacios también íntimos, para llegar a proyectarse a espacios arquitectónicos, urbanos y a la naturaleza. He escogido a esta coreógrafa, aparte de por su brillantez artística reconocida a nivel internacional y porque su obra muestra un claro ejemplo del concepto que trato de transmitir, también porque casualmente este año 2012 ha sido nombrada "Artista de la Ciudad" de Lisboa en la Bienal de "Artistas en la ciudad" y ha participado directamente en varios eventos en el festival "Lisboa na rua", con varias piezas pero principalmente con su proyecto " Bal moderne" en el que intenta acercar la danza contemporánea al público en espacios urbanos.

Fig. 8. Anne Teresa de Keersmaeker. Fuente:

www.magazinedigital.com/reportajes/cie ncia/reportaje/cnt_id/3953

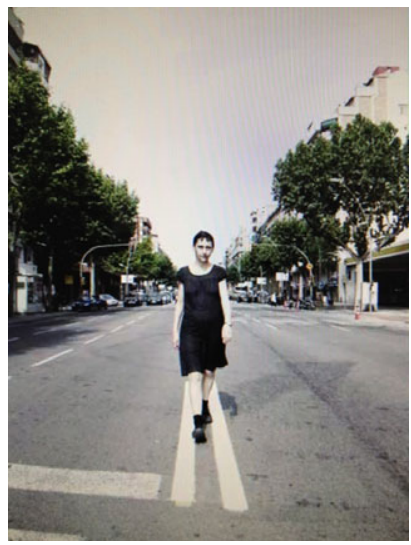

Anne Teresa de Keersmaeker, como heredera de la tradición dancística europea (escuela MUDRA , M. Béjart) y también formada en E.E.U.U. vuelve a Europa e los años 80 cuando el clima artístico permitió a la danza cobrar más protagonismo; aprovechando este momento, va a ser ella quién de un giro a la danza en Flandes. Se trata de una creadora muy plural, siempre en busca de diálogos entre disciplinas, de tránsitos entre el gesto de la creación y la transmisión. Se podría describir su obra como un texto construido, tejido con el movimiento, con los espacios, con la música y con las artes visuales, en el que da mucho espacio al trabajo propio e individual de cada bailarín, sin crear un lenguaje cerrado. Coreografías que muestran una alianza en evolución permanente, entre el sentido refinado de la arquitectura composicional y una fuerte sensualidad y teatralidad. Tres objetivos claros 
destacan en su carrera: 1) Formar su propia compañía "Rosas", Bruselas, 1983. 2) Residencia en la Ópera de la Monaie de Bruselas, 1992-2007. 3) Crear una escuela de danza interdisciplinar que cubra el vacío dejado por MUDRA en 1988: así en 1995 se crea P.A.R.T.S (Performing Arts Research \& Training Studios) donde 60 estudiantes provenientes de 25 países distintos, se forman durante un período de tres años, con más de 50 profesores diferentes. Un trabajo que considera los elementos esenciales de la danza: el tiempo, el espacio, el cuerpo, la voz y su potencial en movimiento, así como la relación de todo esto con el mundo.

\section{Violin Phase 1981-2011.}

- Oh, Sócrates, se diría que obedece a figuras invisibles!

- ¡O que cede a algún noble designio!

- ¡Mira!...!Mira!...ya empieza, ¿lo ves?, andando como los dioses: es sencillamente andar en círculo...empieza por lo más alto de su arte; camina con naturalidad por la cima que ha alcanzado. Esta segunda naturaleza es lo más lejano que hay de la primera, pero es preciso que se le parezca hasta confundirse...se diría que paga el espacio con actos bellos perfectamente iguales, y que acuña con su talón las efigies sonoras del movimiento. Parece enumerar y contar en piezas de oro puro lo que a diario gastamos distraídos en vulgar moneda de pasos cuando andamos en cualquier fin. (Valéry, Paul,

Este 20.04: 95). de Sócrates con Fedro imaginado por Paul Valéry evoca la intimista pieza concebida por ATDK. Se trata del primer solo creado por la artista, en NY en 1981, que un año después fue añadido a Fase: Cuatro movimientos para la música de Steve Reich.

En enero de 2011 se retoma como Performance en el MOMA, formando parte de la serie de Performances y al hilo de la exposición Dibujando a través del siglo XX. El cuerpo como herramienta de dibujo. La danza plasmada en dos dimensiones, pero si se considera una línea como un punto en movimiento, idea base de este proyecto, el acto de bailar se convierte en un dibujo, una inserción de una línea en el tiempo y el espacio tridimensional del mundo que nos rodea. La obra, pensada para observarse desde un punto elevado, se presenta en un espacio público, en un museo como si de una plaza cubierta se 
tratase. Los espectadores van viendo dibujar a la bailarina en la arena blanca con su cuerpo, sus trazos quedan ahí plasmados a modo de lienzo de un pintor. Es el comienzo de una trayectoria que irá abriéndose caminos en los distintos espacios alternativos a un escenario.
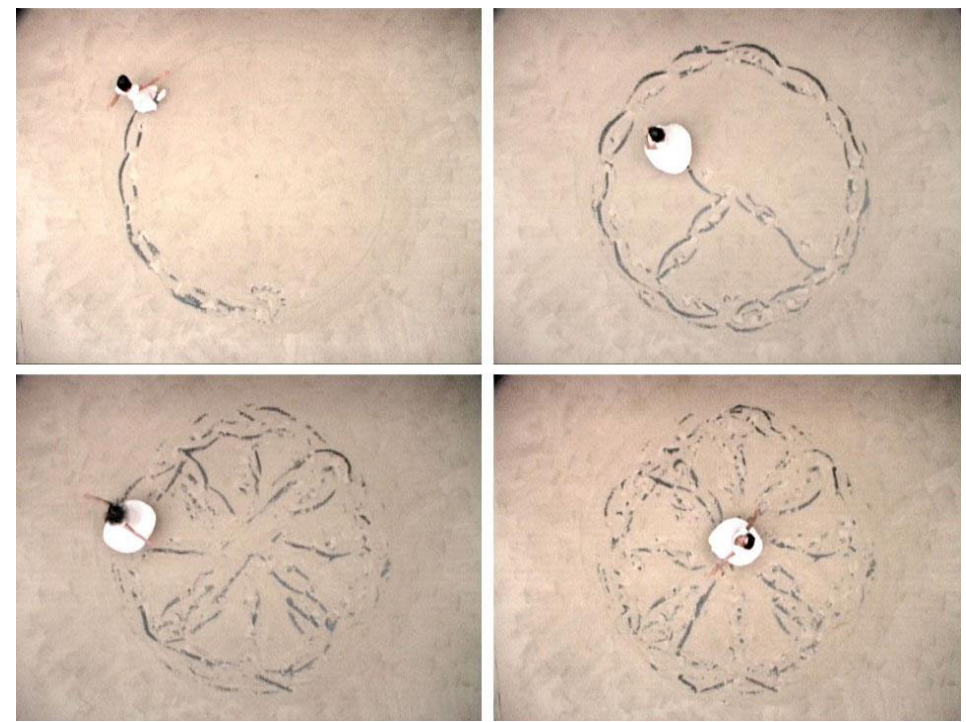

Fig. 9. Anne Teresa de Keersmaeker, Performance MOMA 2011. Fuente: Performance 13: On Line/Anne Teresa De Keersmaeker. Violin Phase from Fase: domusweb.it (disponible en www.youtube.com/watch?v=E1OHl8_MPEg

\section{Ma mère l'oye 2001.}

Esta pieza de video-danza de ATDK junto con el video artista y músico Thierry de Mey, es creada para la música que M. Ravel a su vez compuso en 1912 para unos cuentos de Ch. Perrault de 1697 (mediante la escala pentatónica) se desarrolla en su totalidad en un bosque como telón de fondo. Nos muestra la poesía de la naturaleza a través de la reinterpretación danzada de los cuentos legendario ${ }^{1}$.

\footnotetext{
${ }^{1}$ www.youtube.com/watch?v=hkVk4XPnFxQ - y - www.youtube.com/watch?v=jSP6TT9jJ3E.
} 


\section{Counter Phrases 2003.}

Otro video-danza formado por diez piezas pequeñas fruto de la colaboración artística con diez compositores de música, Thierry de Mey y Anne Teresa de Keersmaeker. Esta vez el telón de fondo va cambiando y muestra un interesante viaje por el "espacio urbano", desde un parque frondoso a modo de "parque inglés", pasando por jardines de estilo versallesco con setos laberínticos, para pasar a una "plaza dura" límite de dicho parque, el "parcours" continúa en pleno centro urbano de una ciudad, se trata de una plaza configurada por edificios administrativos, columnatas y porches son tomados por los bailarines. Dicho peristilo delimita la plataforma que se eleva sobre la ciudad de Bruselas que dibuja su perfil en el horizonte y los bailarines en primer plano trazan movimientos fundiéndose con el paisaje urbano. La danza finaliza con otro parque urbano como telón de fondo².

\footnotetext{
${ }^{2}$ www.youtube.com/watch?v=RBg1eBcELik - y - www.youtube.com/watch?v=Mi9SuGQIVxU.
} 


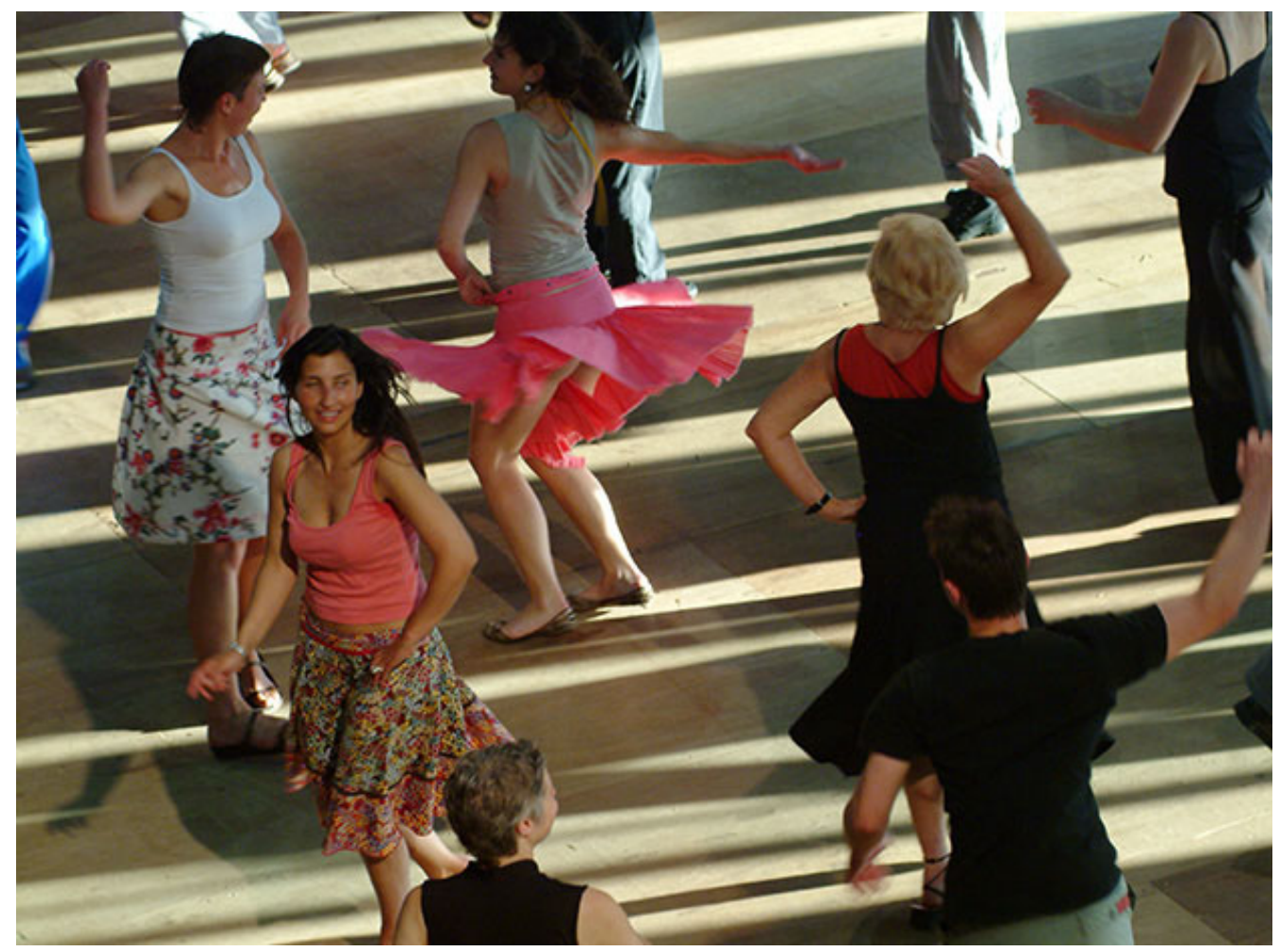

Fig. 10. Bal moderne, Lisboa 2012. Fuente: maisondelaculture.marche.be, www.youtube.com/watch?v=H7lfBIKKYNc y www.youtube.com/watch?v=JPmZfcuDRsI\&feature=related

\section{Ball moderne Lisboa 2012.}

La danza como obra colectiva integrada en la ciudad. ATDK como "Artista de la ciudad 2012" de la ciudad de Lisboa trae su proyecto "Bal Moderne", un intento de hacer llegar su amor por la danza al público, rompiendo las barreras entre audiencia y artista. El evento se venía celebrando en Lisboa desde 1998 y tanto los lisboetas como el equipo de "Bal moderne" han celebrado su vuelta. Es a través de la propia experiencia del público en vez de únicamente observar que se pretende transmitir el entusiasmo por la danza. Se trata de coreografías cortas diseñadas especialmente para este tipo de intérpretes que son mostradas por bailarines en una atmósfera relajada y se efectúan en lugares públicos, en este caso concreto en una plaza (Plaza do Martim Moniz). Gente de todas las edades y estilos de vida se unen por el placer de bailar. 
Como conclusión simplemente recalcar la importancia del espacio en la danza como elemento casi intrínseco a ella y subrayar la progresiva interacción de esta disciplina en todos los ámbitos arquitectónicos, paisajísticos y urbanísticos.

\section{Bibliografía}

ABAD CARLES, A. (2008): Historia del Ballet y dela danza moderna. Alianza, Madrid. CALVINO, Italo (2000): Las ciudades invisibles. Siruela S.A., Madrid.

COLOMÉ, Delfin (1989): El indiscreto encanto de la danza. Turner, Madrid.

DUNCAN, Isadora (2008): El arte de la danza y otros escritos. Akal S.A., Madrid.

GOLDBERG, Roselee (2002): Performance Art. Destino S.A., Barcelona.

KÄSTNER, Irmela y RUISINGER, Tina (2007): Anne Teresa de Keersmaeker. KKiesler, Munich.

KEERSMAEKER, Anne Teresa de y CVEJIC, Bojana (2012): Carnets d'une coréographe: Fase, Rosas danst Rosas, Elena's Aria,Bartok. Fonds Mercator,

LABansaRabdolf von (2003): Espace Dynamique. Nouvelles de danse, Bruxelles.

PALLASMA, Juhani (2010): Los ojos de la piel. GG S.L., Barcelona.

VALÉRY, Paul (2004): El alma y la danza, A. Machado Libros S.A., Madrid.

WELCOME, Bernard (2007): Les Carnets du paysage, Comme une danse. Actes sud et école nationale de paysage, Arles.

ZEGHER, Katerine y MANNING, Erin (2001): Violin Fase. Fonds Mercator, Bruselas.

\section{Recursos web:}

http://en.wikipedia.org/wiki/Thierry_De_Mey

http://fr.wikipedia.org/wiki/Anne_Teresa_De_Keersmaeker

http://invasiondanza.com

http://rosas.foreach.be/fr/rosas

http://www.artistanacidade.com/10/

http://www.britannica.com/EBchecked/topic/81631/Trisha-Brown

http://www.efa-aef.eu/newpublic/upload/efadoc/11/CQD\%20revista\%

$20 \mathrm{sm} \% 20(3) \cdot p d f$

http://www.liveartinstallations.com/100dancers/

http://www.quartierdete.com/programme/spectacles/?id=866

http://www.trishabrowncompany.org/index.php?section=21\#main 
http://www.whattoseeinlisbon.com/es/bal-moderne-lisboa/

http://www.wim-wenders.com/movies/movies_spec/pina/pina.htm 